\title{
Prioritising Research Agenda For E-Commerce In Malaysia
}

Ali Khatibi (Email: ali.khatibi@mmu.edu.my), Multimedia University, Malaysia V.Thyagarajan (Email: venu.thyagarajan@mmu.edu.my), Multimedia University, Malaysia Adeline Chua (Email: adeline.chua@mmu.edu.my), Multimedia University, Malaysia Mohd Ismail (Email: mohd.ismail@mmu.edu.my), Multimedia University, Malaysia

\begin{abstract}
The recent advent of World Wide Web has changed the traditional marketing paradigm in a dramatic way. Under a computer-mediated marketing framework the operations are no longer controlled by boundaries and time constraints. The new paradigm provides firms the whole wired world as potential market to capture. This is the underlying rationale for the Malaysian e-commerce policy or marketing in a "computer-mediated-environment" in Malaysia. Although, the concept of e-commerce is relatively new in this country, but, it was widely accepted marketing medium among the developed nations. Whether Malaysia is able to reap the benefits of e-commerce largely depends on various factors ranging from the infrastructures, the skill base, the critical mass of internet users, legal policy and so on. Understanding the nature of the relationship and the significance of these factors require $a$ good amount of research in the industry perspectives. This paper attempts to provide some guidelines about the research priorities in marketing of Malaysian produce and products under a computer-mediated-environment; taking into account the local and peculiarities of the firms and consumers' behaviour. In this respect the current paper draws literatures about e-commerce experiences of other countries for the purpose of benchmarking. The preliminary conclusion drawn from these literatures suggest that e-marketing outcomes are major reduction in transaction costs and an increase in productivity; which in turn radically change the traditional market structure, behaviour and performance framework. While it is envisaged that the private sector will take the lead role in the development of e-marketing in Malaysia, the government has a bigger role in ensuring its sustainability. The major research issues in economics and marketing are: the competitiveness of the related industries to allow higher investment in bandwidth and high-technology, integration of physical and online marketing, the economics of network management, characteristics and perception of the community on e-commerce, market and commercial governance, the current and future skill of the community, monitoring the changes in marketing functions and intermediary roles and providing macro indicators to measure the market.
\end{abstract}

\section{Introduction}

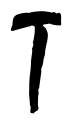

he rapid growth of Internet has transformed it's function from the medium of communication to a brand new market arena (Ricciuti, 1995). The growth of the Internet has led to increase the size of the market with mass consumers and firms participating in a global online market or e-commerce. Internet has been used as a commercial medium for transaction across the borderless world in computer-mediated environment.

The rapid growth of Internet usage as a catalyst of economic growth was advocated by Nielsen Internet Demographic Survey (April 2000) which states that the number of Internet users over the age of 16 in the U.S. and Canada alone has reached 92 million up from 79 million just 9 months ago. Also, the number of women purchasing

Readers with comments or questions are encouraged to contact the authors via email. 
online increased $80 \%$ from the last survey. $13 \%$ of all online buyers made their first purchase in the preceding month. The number one category of items shopped for online was cars and car pats, with $18.2 \mathrm{mn}$ shoppers. Nielsen projected that the Internet population will grow from the current $110.3 \mathrm{mn}$ to $132 \mathrm{mn}$ at the end of the year. Asian countries also exhibited a significant growth in internet usage and its e-commerce application. In many countries namely, Australia, New Zealand, Singapore and Hong Kong are all above the EU average of e-commerce servers per person. And China, which two years ago had no such servers at all, is catching up at a phenomenal pace, growing at an annual rate of more than $1,000 \%$. The ownership of PCs is also rising, albeit from a low base. But at least half those PCs are not connected to a network, having been bought mostly to educate children. More than half of online users in Asia are in business, compared with a third in the United States.

In the Asian region, Malaysia ranks seventh in terms of the number of internet host after Singapore, Israel, Hong Kong, Korea, Taiwan and Japan. Mynic (2000) reported that the number of .COM servers in Malaysia has increased significantly from 100 in 1995 to 4738 in 1999 . These .COM servers account for nearly $90 \%$ of the total servers in the country. IDC Market Research (M) Sdn Bhd estimates that the current number of Malaysian Internet users is about 1.26 million, and is likely to reach 2 million by end of 2000. By 2004, it estimates that the number of users should approach 4 million. Malaysia accounts for about $1.2 \%$ of the total Internet population in the AsiaPacific Rim which is relatively small compared to 30\% (USA), 18\% (Australia), 14\% (Singapore). In 1998, Malaysian spent about RM57mn on e-commerce purchases; a small figure relative to her GDP of RM372bn.

IDC estimates that the number of online buyers in Malaysia will increase from $0.1 \mathrm{mn}$ to $0.87 \mathrm{mn}$ by the year 2003. Further it is estimated that the majority of buyers are expected to come from the home buyer sector, followed by the small business buyers (22.9\%) and medium/large, government and educational buyers with each accounting for $18.3 \%$. But when compared with the various incentive programmes initiated by the government particularly the MSC (Multimedia Super Corridor) and other schemes, the success has been limited.

The sluggish performance could be attributed to its embryonic stage and a combination of socio-economic constraints. For instance, it is cited that e-commerce has not taken off because the country has not achieved a critical mass of local internet buyers because of the attitudinal fear by the internet users.

Secondly; the current logistics arrangements were not correllary to the needs of e-commerce paradigm (Fatimah, 1999). Thirdly, the local consumers are not receptive to the dramatic changes in buying and selling method - from physical transaction to a virtual or online mode. Fourthly, there are serious skepticsm on the issues of security and privacy. Thus, the success of e-commerce in Malaysia hinges on: the closer understanding of the current marketing structure and practices of the local firms and consumers' behaviour (and hence adapting strategies that meet their requirements); an effective policy of network management and infrastructures; and conducive fiscal incentives to the firms. Since e-commerce is a new technology, its proliferation and diffusion require one to identify the specific and peculiar requirements of the industry and hence the need to adjust the technology accordingly. Since e-commerce is still new in the country, research on this subject has been limited with a notable exception of studies by Matrade (1999) and IDC, 1999. These studies however focus on the micro issues of the industry such as the current status of the industry and its readiness in adopting the technology. The scope for further research in ecommerce are enormous particularly in the area of applied research which are technology oriented; secondly macro and micro studies which focus on the economic, management and social perspectives of the e-marketing. Segregation and specialisation of discipline studies are cost effective at times but the nature of e-commerce industry necessitates for inter-disciplinary studies for optimal results. For instance, e-commerce transactions of information at a global scale involve several unsolved issues such as property rights, legal evidence, contract specification, international standards and trade. Hence an examination of the subject must consider issues encompassing such field as economics, legal, political and administrative and technical.

While research agenda on the technology adoption is being formulated and identified by the Malaysian government, agenda but economic and management research about the implementation of e-commerce is still in the refining stage. Hence, technological research is beyond the scope of this paper except when it is an integral part of an analysis. This objective of this paper is to identify major research priority areas in e-commerce both from the macro- (industry) and micro-perspectives (firm level). Because e-commerce is still at a very early stage in its 
development, the theoretical economic framework is still being retuned in the wake of new variables such as nonspatial markets, real time interaction and connectivity of market participants and freedom of market organisation. Empirical statistics on the industry in Malaysia is particularly lacking and not easily accessible. Hence, the discussion of this paper draws mainly on the findings of studies done elsewhere. The approach used in this paper is to derive some implications of other countries' experiences with e-commerce on Malaysia taking into account of the socio-economic characteristics of the country. The likely impact of e-commerce on the industry will be examined using the "structure-conduct-performance" paradigm.

The paper is organised as follows. The initial discussion concentrates on briefly explaining definition of ecommerce, followed by a review of the impact of e-commerce on the new market situation and its impact on economy. The next section presents the rationales of government involvement in these research areas. Identification of research agenda and questions are provided in the consequent section. The paper concludes with the policy implications in the light of the above discussion.

\section{Definition of E-Commerce}

There is no universally accepted definition of e-commerce; it is being defined differently by different authors and different institutions. The simplest definition would be "the buying and selling of information, products, and services via computer networks (Kalakota and Whinston, 1996)." Or, "e-commerce is the act of buying selling goods and services through an electronic medium. It may involve the ordering, payment and delivery of goods and services" (Varbusiness, 1995). IBM defines e-business as "business to vendors, to customers, to employees, and to suppliers via intranets, extranets and the web (internet)".

The various other definitions include: "e-commerce as the application and information sharing technologies among trading partners to the pursuit of business objectives" (MIRL, 1999)." Hoffman and Novak (1999) defined ecommerce along the same line, ie. it is defined as "strategic deployment computer-mediated tools and information technologies to satisfy business objectives".

The above definitions are all logically and technically correct. However, e-commerce encompasses a wide range of electronically enabled business processes and supporting technologies. The business processes and technologies include: electronic data interchange (EDI), electronic funds transfer, e-mail, security, electronic document management, workflow processing, middleware, bar coding, imaging, search and retrieval, agent-based computing, digital signatures, smart cards, voice response, and networking.

In view of the above consideration, the US's NTIA or National Telecommunications and Information Administration (1995) uses a broader definition:, ie. e-commerce "encompasses any use of electronic technology in any aspect of commercial activity". The major activities of e-commerce are:

- $\quad$ Bringing products to market

- $\quad$ Matching buyers with sellers (e.g., electronic malls)

- Communicating with firms/institutions in pursuit of commerce

- $\quad$ Deliver electronic goods (e.g., information)

KPMG (1999) defines e-commerce as "sharing of information, using a variety of electronic technologies, between organisations and individuals for the purpose of doing business with one another". In a nutshell ecommerce is "the commercial transactions and non-commercial actiovities through the use of information technology and network technologies, such as the Internet, intranet and extranets" (ECAC, 1998).

E-commerce is made possible by the Internet - a system of linked computer networks, worldwide in scope, that facilitate data communication services such as remote login, e-mail and newsgroup. The Internet fulfill three commercial functions that facilitate e-commerce activities (Klaus, 1999): they are: 
- $\quad$ Contact - concerning the exchange of information of products and companies

- $\quad$ Contract and distribution

- Integration of three sectors: (a) On the supply side, companies will work together by forming virtual companies (or internet-working); (b) On the demand side users will form a virtual community and; (c) the combination of the two sectors creates the "internet cnglomerates" or the combination of the internetworking and the virtual community.

The major comparative differences in traditional marketing versus internet marketing are summarised in Table 1. The differences lie in every aspect of marketing system - from product definition, pricing, distribution to strategies. E-marketing is carried out in a computer-mediated environment, its platform is online and its scope is global. Hence, marketing functions are carried out every minute with high speed, accuracy and customised to customers' needs. Under such an environment, a new marketing paradigm is being developed where competitiveness is no longer based on the traditional 4Ps idiom but to include standards and customer information. E-commerce firms compete in setting technology standards and on acquiring customer information. As will be shown in the following section, the emergence of e-marketing has transformed the whole system and functions of marketing.

\section{Impact of E-Commerce on the Market}

The general notion of the current literatures available on the impact of e-commerce in financial market is converging towards accepting the market efficiency hypothesis. It is efficient if expectations in the markets are equal to the optimal forecast using all available information. In a non-financial market, an efficient market is created when it is easy for consumers to fully understand a product and when they have the ability to compare product prices in order to make optimized buying decisions. Again, the users' decision is a function of available information. Using this framework, KPMG (1999) that in e-commerce, cost associated with information will decrease because with internet technology, consumers will be able to access information to identify products, prices, vendors and payment scheme. It is highly probable to create an efficient market for mass-produced consumer products under the assumptions of - consumers must have true intelligent agents, network trust and secure payment schemes. In short, market imperfection due to lack of access to market information is being reversed, ie. market participants are overloaded with information in an e-market environment. For the purpose of this paper, some postulations are made on the likely impact of e-commerce on the major dimensions are on market structure, conduct and performance.

\section{Market Structure}

The opening of the world marketspace online cause barriers to entry to lessen significantly both buyers and sellers. In the early stage of internet - marketing, most transactions were custom-made, complex, expensive and the province of large firms. Today, with a small capital base, anyone or firm can become a "trader" and reach millions of consumers worldwide. On the supply side, business-to-business transactions have transformed from known parties to a complex web of commercial activities which involve a vast number of individuals who may never meet. On the demand side, there is a critical mass of consumers participating in a global online marketplace.

The major dimensions of market structure are, competition and extent of concentration, barriers to entry, buyer and seller relationship and product differentiation. The first and obvious impact of this technology is the change in the size of market, ie. with Internet, e-commerce is rapidly expanding into fast-moving, open global market with ever-increasing number of participants. The liberalisation of the telecommunications sector and innovations has greatly expanded the volume and capacity of communications (optic fibre, digital subscriber line technologies, satelites). As mentioned above, the internet community will reach $10 \%$ of the world population in the early millennium and the rate of growth is exponential in nature.

The barriers to entry may not be that low as it seems. According to Hoffmann et. al (1995), ease of access is still the major hindrance to entry. Ease of access is a multi dimensional construct which include high speed access (the bandwith problem), ease of finding a service provider, the diffusion of the computer hardware/softwaremodem bundle into the consumers' home. The secondary barriers are ease of use, price and risk including such as privacy and security. 
Under the traditional marketing system, the buyer-relationship is frequently distorted by market imperfection particularly in terms of information flow. The bargaining position is determined by market power which is directly a function of market information. In terms of buyer and seller relationship, internet marketing results in a personalised relationship between suppliers and their customers, due to their ability to collect information on customer needs and behavioural patterns (Bloch et. al, 1999). In the global information overload community, demand is scarce in comparison to supply (Rayport and Sviokla, (1994). Hence there is a shift from supply side to demand side orientation.

E-marketing displaces, restructures and redefines the role of intermediaries (and hence creates a new form of intermediaries). The traditional intermediaries has to provide infrastructure such as sales network (physical places such as shops, specialised personnel etc.) and managing complexity of handling consumer requests. One of the major consequences of e-commerce is the "disintermediation" or displacement or bypassing the middlemen through the user's ability to connect directly to the source. It has been shown that it has a serious ramifications for middlemen employed as agents, commission agents, stockbrokers, insurance agents or travel agents. These intermediaries as well as many others could be possible phased out as e-commerce becomes more prevalent. These intermediaries will no longer be needed because the monoply on information that they currently hold will no longer be meaningful because the internet will provide universal access and connectivity.

Another new phenomenom in the market is the emergence of new "cybermediaries". The real form, function and definition of the cybermediary is still ambiguos but the circumtances that lead to their existence are clear. These circumtances are: (a) the end user are able to connect directly to the source and hence results in disintermediation, (b) the reversal in directionality of electronic communications - ie. movement of access information has changed from "the centre to user direction" to "end-user to the centre direction". Hence, consumers have stronger bargaining power in the market. (c) The information overload creates new channels of knowledge diffusion and human interactivity. OECD (1998) identifies this new "cybermediary" as navigational tools, software that aids the user locating the information that is relevant to them. Examples of these are Yahoo, Lycos, Magellan and other reference services that allow users to search for Web documents in their data bases. Mitra et. al (1995) define this new breed of middlemen as simply "organisation that perform the mediating tasks in the world of electronic marketing". Forrester Research (1999) classifies these groups into three categories: aggregators, auctions, and exchanges.

Competition in the e-market is no longer centres on the traditional 4Ps idiom but will be more on technology standards. The e-commerce firm competes on technology standard. For instance in the computer and multimedia industries, Novell has become a standard for local area networks while Netscape is trying to build a platform for electronic commerce. Second, firms increasingly compete on acquiring customer information. In fact in customer websites, the platform is shaped around detailed customer information. Such information is used to find new customers more efficiently, improve products and services or tailor them to individual needs and build loyalty. With competition centres on "information content or quality" instead of prices or quantities, problems of asymmetric information and asymmetric access to the electronic link will become more prevalent.

\section{Market Behaviour}

Structural characteristics of a market determine its behaviour. The low barriers to entry characteristic of the e-market or its openness has encouraged firms to allow their business partners and consumers unparalled access to their inner workings, databases and personnel. This has led to a shift in the role consumers, who are increasingly implicated as partners in product design and creation. In short, in the e-market, product decision is made with a direct participation (on-line) from the customers.

Most literature cite reduction in transaction cost as one of the major outcomes that reshapes how firms restructure and compete between and within themselves. Wigand and Benjamin (1996) utilises the transaction cost theory to derive and explain how transaction costs are greatly reduced in e-marketing. Economic theory asserts that firms will choose transactions that economize on coordination costs. With information technology, firms enjoy lower cost of coordination. 
Another, market behaviour namely, matching buyers demand or specification or customization of the product was made easier with electronic communication. Under such a situation it is expected that firms will continue to find incentives to coordinate their activities electronically. Often, this coordination takes the form of single-source electronic sales channels (one supplier and many purchasers coordinated through hierarchical transactions) or electronic markets (Malone et al., 1987). It has been estimated that distribution expenses constitute nearly $65 \%$ of the cost of consumer products. If in a networked economy, these distribution costs could be avoided. Hence, it is reasonable to assume that there could be substantial savings for consumers. Physical distribution costs will be minimised in two ways. Firstly, "close proximity" or direct connection of supplier and customer bypasses numeorus unnecessary intermediaries, hence minimising service charges to these intermediaries. Secondly, cost of inventories are greatly reduced as the faster an input can be ordered and delivered, the less the need for a large inventory. Besides the ability to forecast demand more accurately allows suppliers to adopt "just in time" inventory system. The change in transaction cost in turn affects a firm cost structure of the value added chain.

\section{Market Performance}

The interactive online environment and intangible nature of many products sold online are likely to mean that e-commerce merchants will employ a variety of pricing schemes. The most common is differential pricing. For business to consumer segment, supplier can compile information about consumers' buying habit which allow segementation of the market and make it possible for suppllier to charge different price to different consumers for the same product to reduce the consumer surplus.

The translation of lower transaction cost into lower prices is still not very evidently clear. Many observers predict that electronic commerce will result in very efficient competition that will cause prices to drop and the balance of power toshift from producers to consumers. This has only occured for a few selected products such as commissions for online stock trading.

E-marketing results in the shifting of some marketing cost to the consumers.Some portion of the reduction in firms' cost can be attributed to the shifting of costs formerly borne by the firm to the customer in the form of self servive. For example, customers are now expected to learn about the product, answer their own customer-support question and pay for shipmen $t$ of products.

There is an evidence that firms and establishments adopting new organizational structures have stronger and more productive external linkages with their customers and their suppliers of inputs and services (Canada, 1998). The combination of streamlined business processes, flat organizational hierachy and continuos training and skill acquisition contitutes a favourable environment for innovation and improved productivity.

\section{Government's Role in E-Commerce}

Given its broad impact on the market, economy and social organisation, e-commerce research cannot be delegated solely to the private sector (NSF, 1998). More so in the Malaysian context, where e-commerce is still at its incubation stage with its physical and economic environment are still at the rudimentary level. The government should take the lead role in both basic and applied research to spearhead its growth. From the economics perspective, the importance of government in managing the e-commerce sector can be explained from the resource management viewpoint. Despite the the tremendous growth of e-commerce, large scale of computer network is not necessarily implies efficient resource allocation. High bandwith technology for intance, cannot ensure predictable service quality without proper resource management. The Internet has not only brought in commercialisation and high volumes of traffic in its wake, it has also highlighted inherent shortcomings. In particular the provision for flow control has not been able to address problems of congestion on the Internet satisfactorily (Gupta et. al, 1999).

Large bandwith encourages new users and it gets worse with the proliferation of streaming video, live radio channels and "push content technologies". With a public resource, which is by and large perceived free, no single user has any incentive to control his usage. The net effect of such behaviour can be likened to the Tragedy of the Commons; ie. where common resources are used at sustainable rates as long as the decision making structures 
regarding their management are based solely on the individuals making decisions for their own gain. Besides, ecommerce requires fundamental scientific research which integrate the technological and commercial environment which is best moderated by the government.

By leaving research to entirely to the private sector, certain issues will remain unsolved and inefficiently dealt with. One of the major issues that need to be addressed is the underinvestment by private sector (NSF, 1998). The private sector is expected to be underinvested in some aspects particularly those that are not profit churning activities. For instance, privacy is of fundamental consumer interest but marketplace does not have incentives to cater such interest. Personal information and details are routinely gathered on the Internet for marketing purposes while laws provide minimal guidance and protection of consumers. Although firms do protect consumers' privacy, normally either inadequate measures are taken or their choices may not satisfy the needs of consumers. Other consumer interest that requires protection include: trusted internet infrastructure; and security and reliability in transaction. Technical and legal issues are equally important such as privacy and property rights.

Public goods cannot be adequately dealt with by private institutions. Such examples of public goods are national defense, parks, highways and education. Many products however are partly public and partly private. For instance, education may be considered an essential public service benefitting the society as a whole. In the case of remote education via the Internet, efficient management of network as an educational medium may fall within the boundaries of traditional government concerns. Access to Internet is considered by many as as public a good as highways.

Government is responsible to foster efficient, interoperable, effective and sustainable commerce, ie, it has to minimise market failures due to the unique characteristics of the electronic market - such as peculiarities of spaceless, contactless markets. Major factors that proven to cause market failures are: inconsistent network performance, lack of interconnectivity and interoperability among systems and products, network externalities in communications and softwares. Without intervention and guidance from the governments, e-markets will not function as expected.

The e-commerce industry defies the normal assumptions of traditional market and marketing theories . The digital market is not a linear extension of of the physical economy, rather it has developed into a new realm where the assumptions on time and space variables have changed. Theories on expectations and behaviours of economic and social system largely depend on current formulations and assumptions about firms, market agents, organisations and processes. When this assumptions change, existing models and theories become either irrelevant or unreliable. Hence there is a need to re-examine fundamental assumptions and theories about markets and societies.

The birth of e-commerce is a product of interdisciplinary research in various disciplines such as computer science, software engineering, cognitive pyschology and economics. Consequently the success of the e-commerce will largely depend on the continuous symbiotic collaborartion of these disicplines. The government is the ideal institution to coordinate and monitor such interdisciplinary research.

\section{Research Priorities}

In view of many economic and social benefits of e-commerce, the Malaysian Government initiated many incentive schemes to promote online shopping and to promote e-commerce. The take off however has been very slow (relative to other neigbouring countries such as Singapore, Taiwan and Hong Kong) due to many factors such as: lack of infrastructures, the skill base is still low, inadequate critical mass of internet users and public skepticsm as to security and privacy assurance. The available literature on the various research agenda are very limited In most of the cases it is done on micro level such as the one carried out by Matrade and IDC to find out the extent of IT and internet being used in their institutions and their perception towards e-commerce. These studies are exploratory in nature which are useful in providing an understanding the factors that deter or motivates a firm to adopt e-commerce and hence the need to modify the policy strategies towards fulfilling their requirements. 
Matrade (1999) study shows that almost $70 \%$ of the firms studied use email as one of the communication methods. Between 21-32\% of firm utilise electronic means either for payment (to suppliers and from customers), making orders or receiving orders. About a quarter own product catalogs on the web. Almost $30 \%$ of the firms are currently selling products and services via internet.

The major barriers to adoption of e-commerce include: apprehension on the security and privacy issues, unreadiness to cope with the rapid changing technology, they are not complemented with customers or suppliers who are wired to the network, uncertainties to the rules and regulations on online transaction, high initial investment, lack of skill labour and knowledge to handle e-commerce and so on.

These studies are crucial to the policy makers to find answers as to the factors that inhibit the adoption of ecommerce. While the findings provide some short run solutions, there are other major issues of the industry that require further research to be carried out to ensure sustainability of the industry. Identifying research issues is probably is a formidable task in view of the complexity of the e-commerce environment and matrices which include varibles such as technologies, protocols, systems, applications and business models associated with it. This paper however addresses the major economic and marketing issues while taking into account the interplay of technological infrastructure and commercial environment. NECC (1998) has outlined the major strategic research areas that are necessary to launch the e-commerce project. This section however identifies additional economic and marketing issues (complementing the NECC term of reference) that need to be looked into to ensure sustainable growth of ecommerce in the country. The areas of research prioritised are not confined to the "status quo" needs but also for future consideration. The following paragraphs provide some of the researchable questions:

\section{A. Infrastructure and Infostructure}

Competition policy.Telecommunication industry should be liberalised to allow competition among carriers and for technology convergence. Competition provides the foundation for market growth and investment. How competitive is the telecommunication undustry? Does it encourage investment in high speed networks - which will facilitate the distribution of information, particularly bandwidth-intensive applications which use graphics and video. Issues related here are: should ISP be monopolised or liberalised as in the western countries? In Malaysia this agenda was already been initiated and it has a major role in the growth and development of e-commerce.

Pricing policy and structure. The availability and cost of broadband access are major determinants of ecommerce success. The pricing policy of internet access has to be evaluated in terms of its impact on the industry ie whether it encourages the community to access internet.

The economics of network management. The lifeline of e-commerce hinges on the computers and networks - that play a fundamental role in facilitating online transactions. Establishing an efficient and predictable network is as important as maintaining continuous water supply or electricity to the firm and society. A breakdown in the computer or network will delay the transaction processes or worst still the loss of valuable data either on the suppliers or the users. The relevant question here probably the (a) benefits and costs of centralised vs decentralised management of network; and (b) internet governance.

Network acess and availability. There is a need to identify and transform currently existing business standards from manual to electronic form. How could e-commerce help to improve marketing and business processes? Also the need to harmonise inter and intra sector differences in information system and processes to create a common standard that is converging to the globally accepted standard.

\section{B. Bridging Tradional Production and Marketing/Logistic System and Online Marketing}

Production, marketing (particularly logistic) system and arrangements must be correllary to the online or e-marketing needs. Online marketing is only possible with a strong support of an efficient production, storing, warehousing, trasportation, distribution network in the real or physical market. Online marketing demands fast delivery of customised products which only means production and distribution processes have to be streamlined. 
This implies a need for an understanding the current production and marketing practices of the physical market and analysis should be made on (a) the gap between the offline or physical market and the online market and (b) methods of integrating the traditional system with an identified model of online marketing.

Understanding the consumer behaviour. Old habits die hard. Before participating in the internet marketing, the US consumers have experienced multi-form of transaction methods - face to face, via telephone and mail order. Transition to e-commerce comes in as a natural progression. Marketing techniques other than "face to face" have failed miserably in Malaysia. With this kind of behaviour, it would be useful for firms to understand consumer behaviour in terms of their shopping preferences and utility priorities. The relevant issue to the firms would be - how to translate their preferences into e-marketing strategies and hence aligning their logistic arrangements.

\section{Building Trust in the Transaction}

Trust infrastructure has to be provided to secure electronic transactions. While this is a technological and legal issue, the user perspectives and perception is a social issue. Studies are required to determine the extent and definition of "trust" and "security" that the firms and user need. Trust and confidence as an issue has to adressed from an economic perspective.

\section{Protection of Personal Information}

Encryption products, digital certificates and signatures and other forms of secure and authenticated communications are available for internet transactions but there is no such thing as $100 \%$ security. Hence, while the technology has to be improved, the users have to be convinced and guaranteed of their privacy.

The legal implication is an obvious and urgent one, while a user survey on the users' fear, expectation and level of knowledge is relevant here for policy purposes.

\section{E. Building Skill to the Community}

Skill base labour and community. Digital literacy is required for businesses and consumers to use and develop electronic commerce. Currently, internet users tend to be more educated, affluent and located in urban areas and internet usage is higher in larger companies. The challenge is to expand this usage to a wider spectrum of consumers and all sizes of businesses. Relevant reseach questions here are - what is the digital literacy level of the community? What are the demographic characteristics of the current internet user? Pattern of consumption, perception towards internet/e-commerce and so on.

Preparing skills for the future. Research should investigate the roles played by workers in business reengineering and also the emerging forms of work organisation on e-markets. Hence, the need to address the "upskilling" requirement of these workers and redefining their functions in an e-environment.

\section{F. Commercial Governance}

Monitoring electronic marketplace. Although e-commerce is still small in this country, nevertheless the prospect of growth is promising. To ensure sustainability and stable progress, there is a need for continuous monitoring the organisational impact by firms or sectors at a particular time period. This kind of study would provide valuable inputs for commercial governance, which is critical to the development of e-commerce.

\section{G. Monitoring the Market Competition}

Assessment of the nature of market barriers to entry. The traditional framework of "barriers to entry" analysis may no longer hold due to emergence of new variables in the market such as "interactivity", "connectivity" and "global marketspace" and hence the resultant dimensions. An understanding of the nature and extent of barriers to entry is neccesary to gauge the Malaysia's position in the global e-market. The research could be done at various 
levels. Research could use firm-level data to analyse the competitive behaviour of e-commerce adopters on the domestic and international markets, while sectoral studies could address the dynamics of market structure, particularly in the business-to-business segment. Research on the existence of asymmetries in firms' ability to control access to the e-market will assist policymakers to address competition issues as well as formulate policies for SMEs.

Impact of e-commerce on price/competition. While the general assessment of the impact of e-commerce on prices may be premature, sectoral studies on a variety of consumers and business products should be carried out to measure its impact and identify factors that encourage and inhibit price competition including the use of intelligent agents.

\section{H. Monitoring Market Intermediaries}

Monitoring the restructuring of intermediary functions. The alleged reduction in transaction costs should be translated into lower prices to consumers. Besides it should lead to greater products, market and international competition and greater price competition. While there is limited data to support this alegation, research is needed to identify the change in the intermediary functions and its impact on the market chains.

\section{Indicators For E-Market}

Macro indicators of e-market. The definition of e-commerce or even digital economy is still blurry and questionable due to the complexity and vast technologies that are associated with it. Ambiguity exist in defining products and services transacted in e-market. For instance, products such as CD's, that are now considered goods, have the potential of becoming services in the process of being downloaded. However, since it is a new industry structure altogether, it requires market indicators to measure its performance from time to time. These measurement include price indexes and real output measures, developing new estimates of software investment, improving its measures of output for financial and other services that are major IT-using industries, and working to strengthen estimates of capital stock. This is neccessary to reflect the growing importance of high-tech equipment.

The above list is by no means exhaustive as there are other aspects of e-commerce which are of equal importance to the industry such as legal issues, audit,regulation, antitrust enforcement, intelectual property, privacy and technology fundamentals.

\section{Conclusion}

The internet has turned the marketing system of goods and services upside down and inside out. Despite the rapid and unpredictable upsurge, e-commerce has been shown to bring about growth and large profits in business to business and business to consumers world wide. Although currently this phenomenum belongs to the US market (it accounts about $80 \%$ or the world e-commerce), the openness of the e-market makes it an attractive ground for other countries to participate. Malaysia has taken the right policy path to launch e-commerce to impove her competitive edge in the global market.

The general literatures show that e-commerce has evolved and grown at an unprecedented speed and scale respectively in a very short time. It was driven solely by technology; inevitably technology is its very essence. It's functions are closely intertwined with technological devices and system. For instance, the issue of "trust" is not just a legal matter but more of a technological one. The same applies to issues on privacy, intelectual property, security, network stability and so on. Given the current state of art of IT and digital literacy in Malaysia (which are categorised in the "third wave" of the IT revolution), it is not suprising to see that e-commerce has not progressed as fast as other developed countries. The adoption of e-commerce is further hindered by lack of infrastructures, users' uncertainties on issues such as security, privacy, inadequate critical mass of internet users, consumers' habits and so on. 
Clearly technological infrastructures and digital literacy should be given the first priority in the resarch agenda. Some of these problems are being addressed by the government through her MSC and related projects. The author believes that there are additional economic and marketing questions and issues that have to be answered through research in order to understand why it has not taken off as it should and also how the industry should be monitored in the future. These issues and questions include: the competitiveness of the related indutries to allow higher investment in bandwidth and high technology, the economics of network management, integration of traditional and e-marketing methods, characteristics and perception of the community on e-commerce, market and commercial governance, the current and future skill of the community, monitoring the changes in marketing functions and intermediary roles and providing macro indicators to measure the market.

\section{References}

1. Access Media International, (1999). http:///ami-usa.com

2. Anderson, C., Electronic Commerce: A Survey, The Economist, May 10th, 1997.

3. Bloch, M, Yves Pigneur \& Arie Segev (1999) On the Road of Electronic Commerce -- a Business Value Framework,

4. Gaining Competitive Advantage and Some Research Issues. http://haas.berkeley.edu/ citm/roadec/ec.htm\#sec4

5. Canada (1998).Task Force of Electronic Commerce, http://strategis.ic.gc.ca/SSG/it03472e.html

6. ECEAC (1998). Report of The Electronic Commerce Advisory Council State of California. http://www.ecommerce.ca.gov/1c_intro.html

7. Fatimah Mohd Arshad (1999). E-commercialising Agricultural Marketing in Malaysia. Paper presented at the PETA-JPSM-PKD seminar on "Repositioning of the Malaysian Agriculture in the Next Millennium," 13-14 July, Serdang, UPM. http://www.econ.upm.edu.my/ peta/fatimah.html

8. Gupta, Alok, Boris Jukic, Manoj Parameswaran, Dale O. Stahl, Andrew B. Whinsto (1999). Streamlining the Digital Economy: How to Avert a Tragedy of the Commons http://yama.bus.utexas.edu/ intereco/overview.html

9. Forrester Research (1999)."Anatomy of New Market Models," Varda Lief, February. http://www.forrester.com

10. International Data Corporation, (2000) http://www.idc.com/Data/AsiaPacific/default.htm

11. IITA (1994). Electronic commerce and the NII. Information Infrastructure Technology and Applications Task Group, National Coordination Office for High Performance Computing and Communications, February, 13-4.

12. Jaring Internet Magazine (2000). http://www.jaring.my

13. Kalakota, R. and Andrew Whinston (1996). Frontiers of Electronic Commerce. Addison- Wesley.ISBN:0201-84520.

14. Klaus, von Versen (1999). The Three Commercial Functions of the Internet. http://www.electronicmarkets.org/netacademy/publications.nsf/all_pk/1249

15. Matrade (1999). Matrade E-Commerce Survey result http:// www.matrade.gov.my/trdmartjuly2.html

16. MDC (1998): New Frontiers in E-Commerce http://www.mdc.com.my/msc/flagship/bm.html

17. Mitra B. S., Brian Butler and Charles Steinfield (1995) Intermediaries and Cybermediaries: A Continuing Role for

18. Mediating Players in the Electronic Marketplace. http://www.ascusc.org/jcmc/voll/issue3/sarkar.html

19. The Future of Electronic Commerce over the Internet and Its Effect on Market Efficiency, Socio-Economic Policy, Risk, Control, and Audit Theory http://www.kpmg-ecom.se-com.com

20. The Economic and Social Impacts of Electronic Commerce: Preliminary Findings and Research Agenda

21. http://www.oecd.org/subject/e_commerce/ebooks/055-078.pdf

22. Hoffman, D. L., \& Novak, T. P. (1994b). Building new paradigms for electronic commerce. Hot Wired (Intelligent Agent Section), December 29. http:// www2000.ogsm.vanderbilt.edu/intelligent.agent/ index.html

23. Hoffman, D. L., \& Novak, T. P. (1995). Marketing In hypermedia computer- mediated environments: Conceptual foundations. Revised July 11 . http://www2000.ogsm.vanderbilt.edu/ cmepaper.revision.july11.1995/cmepaper.html 
24. Hoffman, D.L., Novak, T.P., \& Chatterjee, P. (1995). Commercial scenarios for the Web: Opportunities and challenges. Journal of Computer-Mediated Communication [On-line], 1 (3). http://www.ascusc.org/ jcmc/vol1/ issue3/hoffman.html

25. Hoffman D. L., T. P. Novak, and P. Chatterjee (1995): Commercial Scenarios for the Web: Opportunities and Challenges. http://www.ascusc.org/jcmc/vol1/issue3/hoffman.html

26. Hoffman D. and T. Novak (1999). What is E-Commerce? http://ecommerce.vanderbilt.edu/novak/ what/sld009.htm

27. Malone, T., Yates, J., \& Benjamin, R. (1987). Electronic markets and hierarchies. CACM, 485.

28. Merrill Lynch, 1999. E-Commerce: Virtually Here.

29. MYNIC STATISTICS (2000). http://www.mimos.my/mynic.html

30. MIRL (1999). Electronic Commerce Partner. http://www.nemonline.gov/mirl/ec/primer.htm

31. NECC (1998).Strategic Directions and Success Strategies of Electronic Commerce in Malaysia http://www.e.ec.my

32. NTIA Office of Assistant Secretary. (1995). Electric Commerce. http://www.ntia.doc.gov:80/ opadhome/ecom3.html

33. NSF (1999). NSF Workshop: Reseacrh Priorities in Electronic Commerce. http://cism.bus.utexs.edu/ workshop/ ecdraft.html

34. The CommerceNet/Nielsen Internet Demographic Survey April 1999 Internet Demographic Highlights http://www.commerce.net/research/stats/april99.html

35. Rayport J. F. and John. J. Sviokla, (1994). Managing in the Marketspace. Harvard Business review, Nov 72(6):141.

36. Wigand R.T. and R.I. Benjamin (1996). Electronic Commerce: Effects on Electronic Markets. http://www.ascusc.org/jcmc/vol1/issu3/wigand.html

Notes 